\title{
Non-Linear Finite Element Analysis of RC Deep Beam Using CDP Model
}

\author{
Pramod Rai* \\ Span Systems International Co. Ltd., Phayathai, Bangkok, Thailand \\ Received 19 March 2020; received in revised form 23 July 2020; accepted 20 August 2020 \\ DOI: https://doi.org/10.46604/aiti.2021.5407
}

\begin{abstract}
Finite element analysis (FEA) is widely adopted these days to investigate relatively heavy structures such as reinforced concrete (RC) deep beam, which requires a higher investment of resources. This research aims to investigate a numerical modeling technique applicable to study the nonlinear behavior of RC deep beams by using FEA based on the software, ABAQUS. The nonlinear behavior of an RC deep beam adapted from an earlier research work is captured by using the uniaxial compressive and tensile stress-strain relationship and damage parameters of concrete. The response of the FE model is verified with the experimental results in terms of the load to midspan deflection curve and damage distribution. The ultimate shear capacity predicted by the FE model is $0.75 \%$ lower, and the corresponding displacement is $6.92 \%$ higher than the experimental results. The adopted modeling technique and the constitutive concrete models demonstrate the promising results indicating its possibilities for the investigation of RC structures.
\end{abstract}

Keywords: nonlinear finite element, reinforced concrete deep beam, concrete damage plasticity, abaqus

\section{Introduction}

The 3-dimensional finite element modeling (FEM) of RC structural systems or components can reflect the behaviors close to the experimental tests. However, the realistic simulation of concrete material is complicated when it deals with the nonlinear behavior of the materials. Most importantly, the nonlinear constitutive characteristics of concrete, tension cracks, compression crushing, and bonding between steel and concrete, etc. cause difficulties in the modeling of RC [1-2]. Nevertheless, with the proper understanding of such subject matters and following appropriate modeling techniques, the FEM can be used to investigate and realize the behaviors of the RC structures that are even difficult to produce and test in the laboratory environmental conditions

A deep beam is a widely used structural component in RC buildings these days, especially in high-rise buildings, such as footings, foundation pile caps, floor diaphragms, shear walls, etc. A typical RC deep beam constructed in the department of civil engineering, Kasetsart University, Thailand is shown in Fig. 1. According to ACI 318-14 [3], a deep beam is defined as the structural member having a shear span-to-depth $(\mathrm{a} / \mathrm{h})$ ratio less than 2 and having a clear span not exceeding four times the overall member depth $(\mathrm{L} / \mathrm{h}<4)$.

Due to the nonlinear strain distribution over the depth, the Bernoulli hypothesis is not valid in these beams. Furthermore, deep beams are relatively difficult and require a higher investment of resources to investigate through the experimental test. For instance, performing an experimental study of deep beam requires high capacity test setup, more instrumentation, and higher human and financial resources. Besides, the strength of the deep beam is altered by the size of the specimen, precisely

* Corresponding author. E-mail address: pramodwrai@gmail.com

Tel.: +064-940-7662 


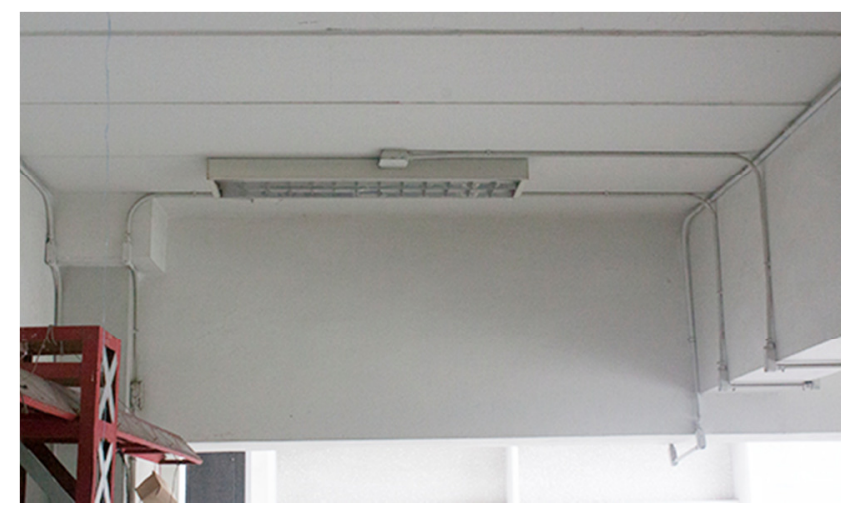

Fig. 1 A typical RC deep beam in an RC building

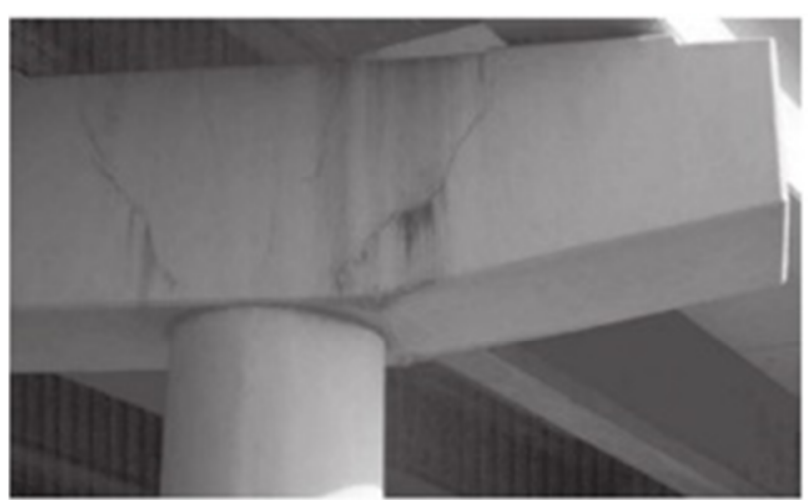

Fig. 2 A cracking in RC bent caps [5]

referred to the size effect [4]. Thus, any kind of alternation in dimensions of the beam results in a complicated scenario. Fig. 2 shows a typical failure of the RC deep beam. The flexural-shear cracks in an RC deep beam propagating from the girder loading points to the supporting column [5].

ABAQUS, a FEA based on software package, has dedicated its effort in the modeling of the concrete material models that have proven to be effective in realistic simulations by several researchers [2, 6-7]. Mainly, two approaches have been adapted by the researchers for the investigation of concrete material: a smeared crack model and concrete damage plasticity (CDP) model. According to the user's manual, the first approach can be applied for the models subjected to monotonic loading, while the other can be used in monotonicity as well as cyclic loading scenario [8]. Several studies have been performed successfully by using both material models, and the CDP model is used in this study. The CDP model adopts the yield function given by Lubliner et al. [9], and the other adopts the yield function modified by Lee and Fenves [10], in which the yield surface is defined in the plane stress and deviatoric plane conditions.

Earij et al. [7] investigated the behaviors of RC beams by using a dynamic explicit procedure together with the CDP model to simulate the loading-unloading-reloading behavior of the beams and to predict their crack patterns. Mohamed, Shoukry, and Saeed [2] studied the RC deep beams with web openings under static loading conditions. Hamoda et al. [11] performed the numerical assessments of RC beams with distributed depths along with experimental verification. Likewise, Hamdolah, Kuang, and Bijan [12] verified the predictability of the model by simulating the behavior of four full-scale and the exterior wide beam-column connections tested under reversed cyclic loadings. Similarly, Nzabonimpa, Hong, and Kim [13] used the CDP model to reproduce the experimental response of the mechanical beam-column joints of precast based frames. The authors also proposed a nonlinear finite element model based on CDP for the precast concrete beam-column jointed by mechanical plates.

Genikomsou and Polak [14] performed 3-dimensional analyses of RC slab-column connections under static and pseudo-dynamic loadings to investigate their failure modes in terms of the ultimate loads and cracking patterns. It also reported that with the appropriate modeling of element size and mesh, and the constitutive modeling of concrete, the CDP model could predict the punching shear response of the slabs. To note, all the above-mentioned studies have emphasized that an accurate prediction of the concrete behavior could not be achieved by using the CDP model unless the appropriate parameters are carefully chosen, and the hardening/softening rules are applied with proper conception.

The main objective of this study is to demonstrate a complete 3-dimensional FE modeling technique, including a reliable constitutive model and damage parameters of concrete, and to simulate the nonlinear behavior of RC deep beams by using the CDP model available in ABAQUS. The investigation adopts the damage parameter proposed by Birtel and Mark [15] which has rarely been used for the simulation of real structures. The devised technique and the material models are validated by using the result obtained from the experimental results available in the literature in terms of load-to-midspan deflection and damage patterns. 


\section{Experimental Study}

The experimental test of an RC deep beam carried out by Demir, Caglar, and Ozturk [16] was adopted as the reference for the numerical modeling in this investigation. The geometry of the reference beam named DB60/1.86-C1/SR is shown in Fig. 3. According to the reference, the beam specimen was designed per the requirements given in the ACI 318-14 code for RC deep beams and in a way that nodes and ties had adequate strengths to ensure the shear failure. The adequate sizes of load and support plates were selected to supply the sufficient confinement at nodes and thus to skip the failure. Likewise, the standard ribbed reinforcing bars are used in the specimen to avoid failure at the nodes. The horizontal web reinforcement was spaced at $160 \mathrm{~mm}$, and the vertical stirrups were spaced at $180 \mathrm{~mm}$.

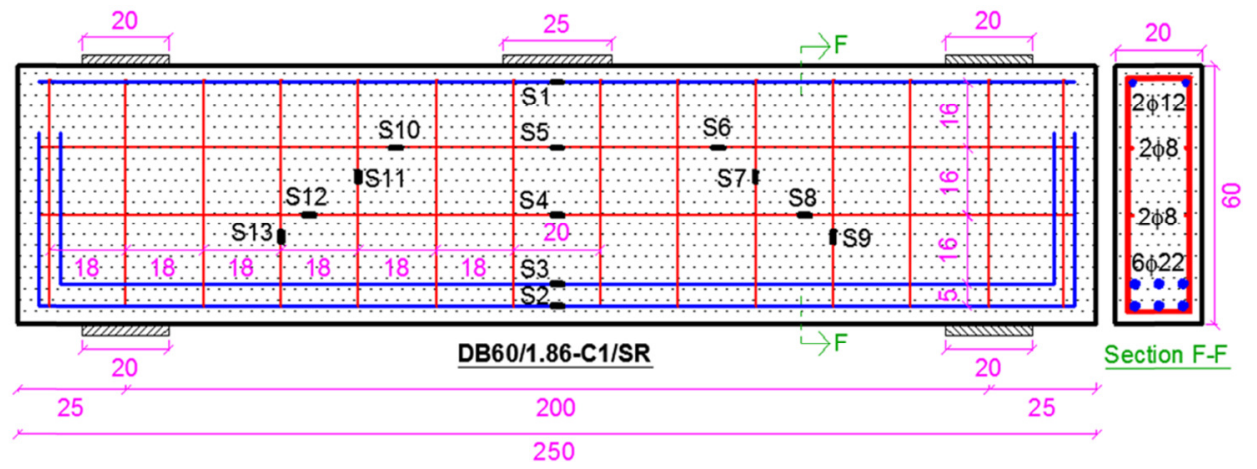

Fig. 3 The detailed drawings of the specimens (units in cm except for diameter of reinforcement in $\mathrm{mm}$ ) [16]

The 28-day compressive strength of the concrete $\left(f_{c}{ }^{\prime}\right)$ used in the specimen obtained from the compressive strength test of the cylinder is $18.1 \mathrm{MPa}$. Comparably, the yield strength of tension reinforcement (6-22 mm in diameter) is $482 \mathrm{MPa}$, whereas the yield strength compression reinforcement (2-12 $\mathrm{mm}$ in diameter) and web reinforcements (8 $\mathrm{mm}$ in diameter) are $421 \mathrm{MPa}$.

The beam specimen was subjected to a monotonic vertical static loading at the midspan via a hydraulic cylinder, and the applied load was measured through a load cell placed between the hydraulic cylinder and the specimen. The vertical displacements occurring at the bottom of the specimen were measured by the linear potentiometer. The beam supports consisted of a pin and a roller in the test. Moreover, the top and bottom surfaces of the specimen at supports were tied and fastened to each other through steel rods to prevent the out-of-plane movement as shown in Fig. 4.

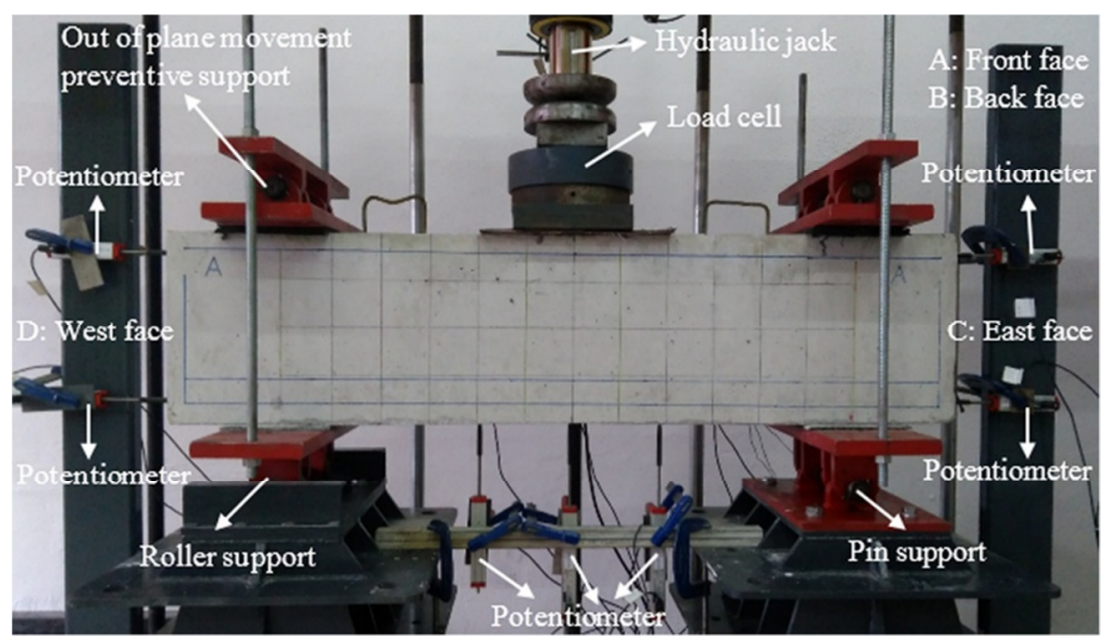

Fig. 4 The test setup and measurement devices [16]

The load to the midspan deflection curve of the beam specimen obtained from the experimental test of the beam specimen is illustrated in Fig. 5. Since the tabular data of the beam specimen was not provided in the reference study, the curve was traced manually from the available research paper. According to the reference study, the critical cracking load corresponding to the initiation of the first shear crack of the specimen is equal to $235 \mathrm{kN}$. Beyond that point, the diagonal cracks initiated 
simultaneously in both the shear spans throughout the strut axes. With further increase in the applied load, the gradual increase of the diagonal crack widths was observed until a sudden and brittle shear failure of the beam specimen occurred upon reaching the ultimate load-bearing capacity of struts. The failure mode of the beam specimen is a diagonal splitting failure at the ultimate stage.

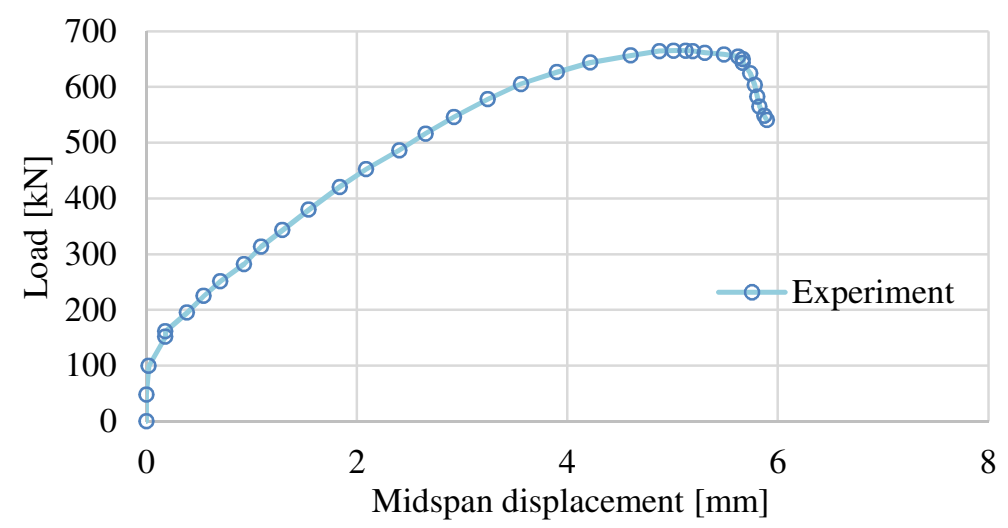

Fig. 5 The experimental load to the midspan deflection response of the beam specimen [16]

\section{Finite Element Modeling}

\subsection{Material modeling}

Two types of techniques are available in Abaqus for the simulation of concrete behavior: a smeared crack model and a CDP model [8]. The CDP model of concrete requires the concrete compressive and tensile constitutive relationship, cracking and crushing damage parameters, and other material parameters, such as the dilation angles, eccentricity, biaxial compressive strength to uniaxial compressive strength ratio, the coefficient $\mathrm{K}$, and viscosity parameters [8]. Various researchers have provided the reference values for the above-mentioned FEA parameters. For instance, Nzabonimpa, Hong, and Kim [13] have adopted the dilation angle values from $30^{\circ}$ to $56^{\circ}$ in order to calibrate the simulation of the beam-column joints. Similarly, Hamdolah, Kuang, and Bijan [12] have recommended the values in the range of $38^{\circ}$ to $42^{\circ}$. The various parameters obtained from several trials and adopted in this research are demonstrated in Table 1.

Table 1 The CDPM parameters for concrete materials in Abaqus

\begin{tabular}{|c|c|c|}
\hline Parameter & Value & Description \\
\hline$\varphi$ & 33 & Dilation angle \\
\hline$\varepsilon$ & 0.1 & Eccentricity \\
\hline$f_{b 0} / f_{c 0}$ & 1.16 & $\begin{array}{c}\text { The ratio of initial equibiaxial compressive strength } \\
\text { to initial uniaxial compressive strength. }\end{array}$ \\
\hline$K\left(K_{c}\right)$ & 0.667 & $\begin{array}{c}\text { The ratio of the second stress invariant to the tensile } \\
\text { meridian }\end{array}$ \\
\hline$\mu$ & 0.001 & Viscosity parameter \\
\hline
\end{tabular}

There are several analytical constitutive models suggested for concrete materials. The stress-strain curve of the concrete in compression used in this investigation is illustrated in Fig. 6. The stress-strain relationship that was first proposed by Popovics [17] and later modified by Thoronfeldt et al. [18] was adopted in this research. According to this model, the stress-strain relationship of concrete in compression is obtained by:

$$
f_{c}=\frac{n f_{c}^{\prime}\left(\frac{\varepsilon_{c}}{\varepsilon_{c 0}}\right)}{(n-1)+\left(\frac{\varepsilon_{c}}{\varepsilon_{c 0}}\right)^{n}}
$$


where $f_{c}^{\prime}$ and $\varepsilon_{c 0}$ are the compressive strength and strain corresponding to maximum stress, respectively. The ' $\mathrm{n}$ ' in Eq. [3] is defined by $[1,18]$ :

$$
n=0.4 \times 10^{-3} f_{c}^{\prime}(p s i)+1.0
$$

The stress-strain relationship of concrete in tension is assumed to be linear up to the uniaxial tensile strength. The stress-strain curve of the concrete in tension and used in this investigation is shown in Fig. 7. For the tension softening part, the relation is determined by using the exponential function proposed by Belarbi and Hsu [19-20] as demonstrated in Eq. (3) and Eq. (4):

$$
\begin{aligned}
& \sigma=E_{c} \varepsilon \text { if } \varepsilon \leq \varepsilon_{t} \\
& \sigma=\sigma_{t}\left(\frac{\varepsilon_{t}}{\varepsilon}\right)^{0.4} \text { if } \varepsilon>\varepsilon_{t} \\
& E_{c}=4700 \sqrt{f_{c}^{\prime}(M P a)}
\end{aligned}
$$

where the modulus of the elasticity of the concrete is determined by using the equation prescribed in ACI 318-14 as expressed in Eq. (5).

The tensile strength of concrete is determined by:

$$
\sigma_{t}=0.62 \sqrt{f_{c}^{\prime}(M P a)}
$$

Similarly, the tensile strength of concrete and the corresponding strain is obtained by:

$$
\varepsilon_{t}=\frac{\sigma_{t}}{E_{c}}
$$

The steel reinforcements and steel plates are modeled as elastic-perfectly plastic materials with the yield strength of 482 $\mathrm{mPa}$ and the Poisson's ratio value of $\vartheta=0.3$ behaving similarly in tension and compression. The Poisson's ratio used for the concrete is equal to 0.18 .

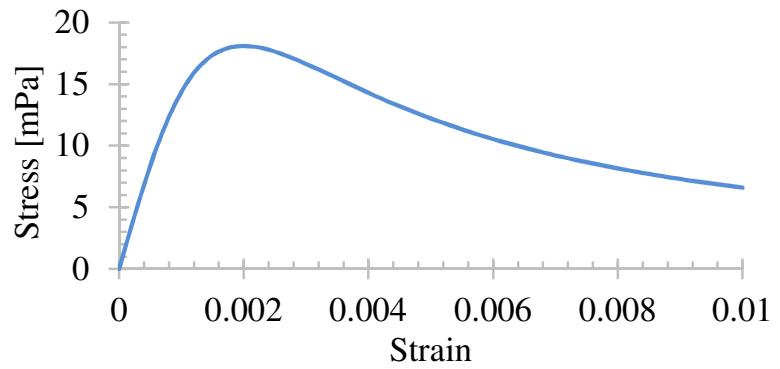

Fig. 6 The concrete uniaxial compressive stress-strain diagram

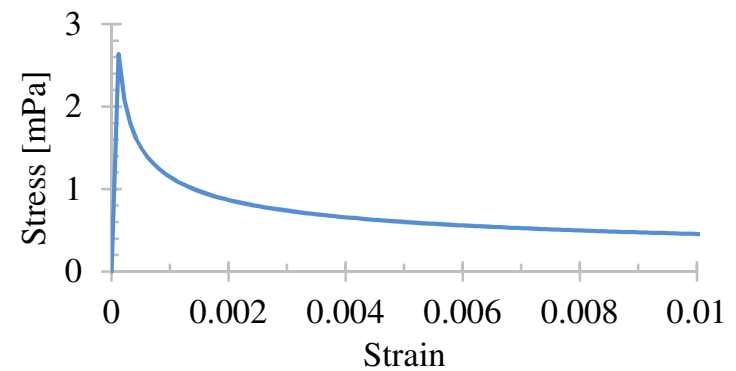

Fig. 7 The concrete uniaxial tensile stress-strain diagram

In addition to the constitutive model and CDP parameters, the CDP model of concrete material in Abaqus requires the definition of the compression and tension damage parameters which take account of the concrete crushing and cracking behavior, respectively. These damage parameters can take values, 0 and 1 represent no damage and fully damaged condition of the concrete, respectively. The damage parameters in compression and tension are defined based on the equation given by Birtel and Mark [15] and expressed by Eq. (8) and Eq. (9), respectively. 


$$
\begin{aligned}
& d_{c}=1-\frac{\sigma_{c} E_{c}^{-1}}{\varepsilon_{c}^{p l}\left(\frac{1}{b_{c}}-1\right)+\sigma_{c} E_{C}^{-1}} \\
& d_{t}=1-\frac{\sigma_{t} E_{c}^{-1}}{\varepsilon_{t}^{p l}\left(\frac{1}{b_{t}}-1\right)+\sigma_{t} E_{C}^{-1}}
\end{aligned}
$$

The damage parameters in compression and tension are illustrated in Fig. 8 and Fig. 9, respectively. The coefficients $b_{c}$ and $b_{t}$ take values in the range of 0 to 1 . Birtel and Mark [15] suggested $b_{c}=0.7$ and $b_{t}=0.1$ respectively, based on the experimental test results. However, after numbers of trials, the values $b_{c}=0.7$ and $b_{t}=0.4$ are found to provide a convergent solution for the FE model adopted in this study.

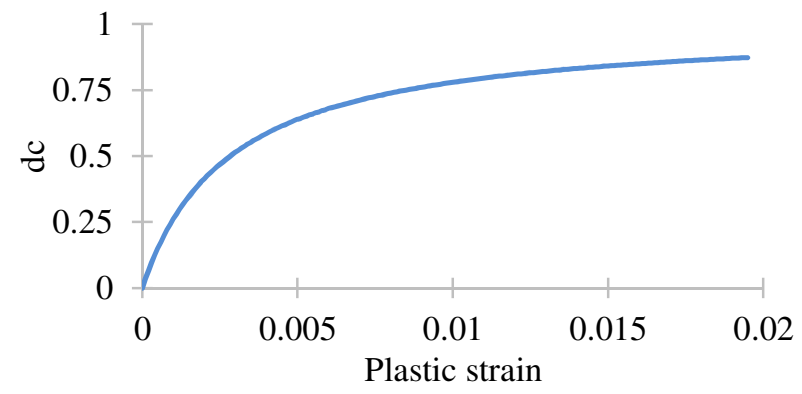

Fig. 8 The uniaxial compression damage parameter of concrete

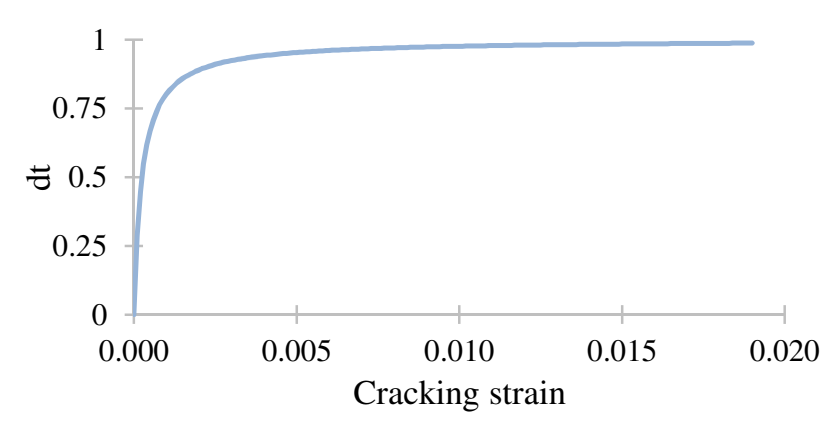

Fig. 9 The uniaxial tension damage parameter of concrete

\subsection{Element type and meshing scheme}

The steel reinforcements are modeled by using a 2-node truss element (T3D2), and the concrete is modeled by using an 8-node solid finite element (C3D8). Similarly, the solid finite element is used to define the plates at supports and the loading point.

A parametric investigation is performed to find the most accurate mesh size for the FE model. As a result, an optimum mesh size is determined as $40 \mathrm{~mm}$ with an aspect ratio of nearly 1. A 3D model of the meshed concrete beam is shown in Fig. 10. All the reinforcements and plates are meshed with a finite element size of $40 \mathrm{~mm}$.

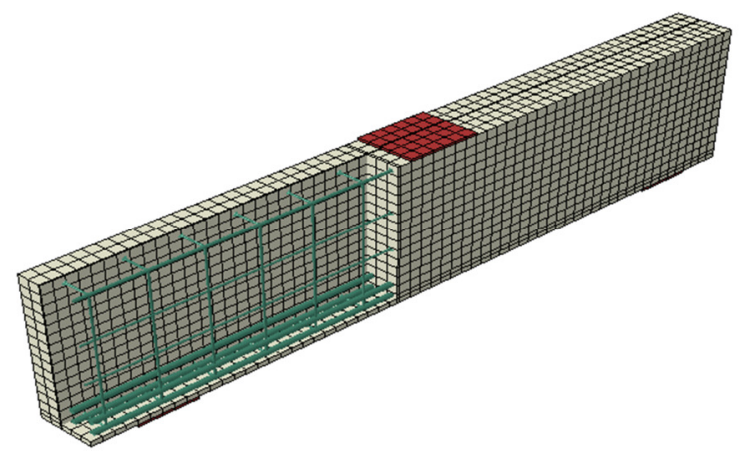

Fig. 10 The 3D model of the beam with the embedded rebar

\subsection{Material bonding and boundary conditions}

The steel reinforcements are embedded inside the concrete solid elements which don't allow the slip of the reinforcement. When the truss element of reinforcement is embedded inside the host concrete solid element, the translation degrees of freedom of the embedded node are constrained to be the interpolated values of the corresponding degrees of freedom of the host 
elements [8]. Further, the contact between the surfaces of concrete and the steel plates is assigned as the tie constraint. A surface-based tie constraint in Abaqus ties the two separate surfaces together so that there is no relative motion between them; thus, the translational and rotational motion, as well as all other active degrees of freedom, are equal for the paired surfaces [8].

At one of the end supports, the translation degrees of freedom are constrained in all directions, which represents the pinned-support, whereas at the other end, the translational and rotational degrees of freedom in the $\mathrm{X}$ - and $\mathrm{Y}$-direction are made free, which represents a roller support condition.

\section{Results and Discussion}

The comparison between the load to the midspan deflection response obtained from the experimental test, and the FEA result is demonstrated in Fig. 11. In the initial loading stage, the response of the specimen from both approaches is very close to each other. When the applied load is close to the value of the critical cracking load, $235 \mathrm{kN}$ (Fig. 11), the load-to-midspan response of the FE model begins to become slightly stiffer than the test result. The difference in the stiffness continues almost near to the ultimate loading stage. However, shortly after the ultimate loading stage, the responses of the beam specimen from both approaches abruptly decline and indicate the brittle shear failure modes.

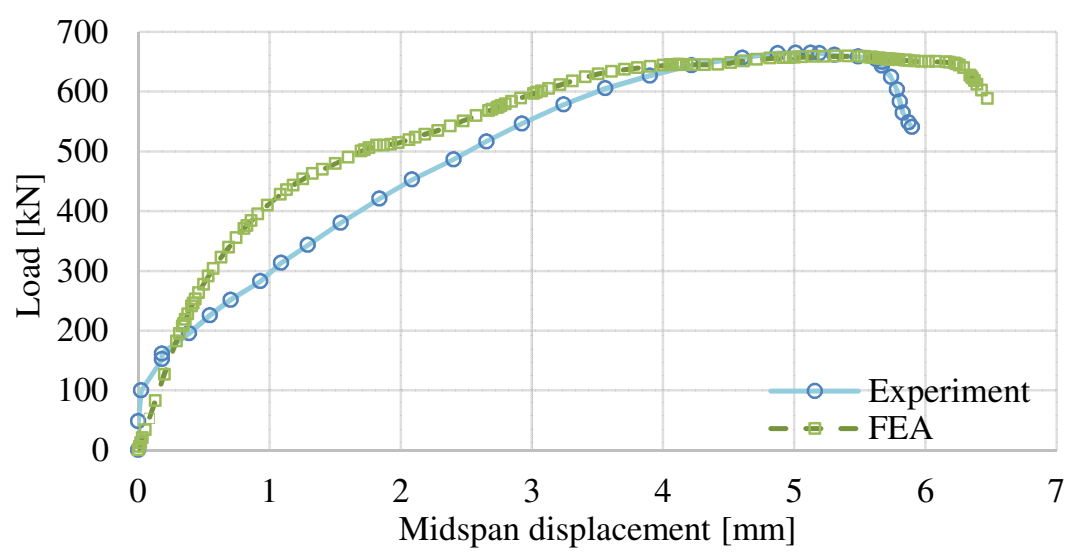

Fig. 11 The comparison of the experimental results with FEA

Eir widths continue after the critical cracking loading stage. Nevertheless, such kind of micro-crack effects is not included in the FE model [8]. The higher stiffness in the response of the FE model, compared to the experimental test, nearly after the critical loading stage (Fig. 11) have resulted due to the occurrence of the micro-cracks in the concrete material during the experiment. When the applied load is increased further, the stiffness of the FE model begins to reduce gradually and is close to the experimental test result. Such a reduction in stiffness in the FE model is caused by the increase in the magnitude of the principal strains responsible for the diagonal tensile failure and the compression crushing of the concrete material as depicted by the stress-strain relationship in Fig. 6 and Fig. 7. As the value of the maximum principal strain (tensile strain) exceeds the strain value corresponding to the tensile strength of the concrete, and the minimum principal strain (compressive strain) value exceeds the strain value corresponding to the compressive strength of the concrete, the stiffness of the beam initiates to reduce. This is the reason for the decrease in the stiffness of the FE model at the higher loading stage.

When the applied load reaches $659 \mathrm{kN}$, the stiffness of the FE model drops suddenly and indicates the brittle shear failure. The corresponding midspan deflection is equal to $5.41 \mathrm{~mm}$. In the experimental test results, the ultimate shear failure of the beam specimen occurrs at $664 \mathrm{kN}$, and the midspan displacement at this stage is $5.06 \mathrm{~mm}$. Thus, the ultimate loading capacity predicted by the FE model is $0.75 \%$ lower, and the corresponding midspan displacement is $6.92 \%$ higher than the experimental test results. It is evident that the FE model reflects the load to the midspan behavior of the deep beam close to the experimental test results. Especially, the ultimate shear failure behavior of the experimentally tested beam specimen is reflected precisely by the FE model. 
In addition to the load to midspan response, the damage distributions of the experimentally tested specimen during the ultimate loading stage are compared to the simulated model. The ultimate failure damage during the experimental test is illustrated in Fig. 12, in which the diagonal shear crack running from the loading point to the support diagonally can be seen clearly. According to the reference, the beam specimen fails in the diagonal splitting failure mode. The damage distribution in the FE model in terms of the maximum principal plastic strain (PE-Max. principal) is shown in Fig. 13, and the directions of such strains are presented graphically in Fig. 14. On the basis of the user's manual, the value of the maximum principal plastic strain is the main indicator of crack initiation in the concrete damage plasticity model in ABAQUS.

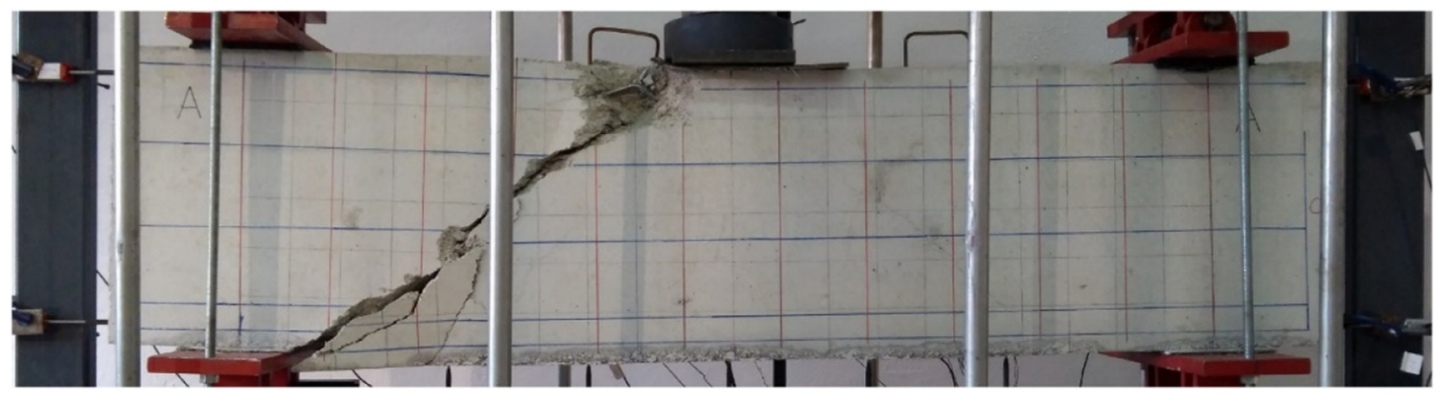

Fig. 12 The ultimate failure damage of the specimen in the tests [16]

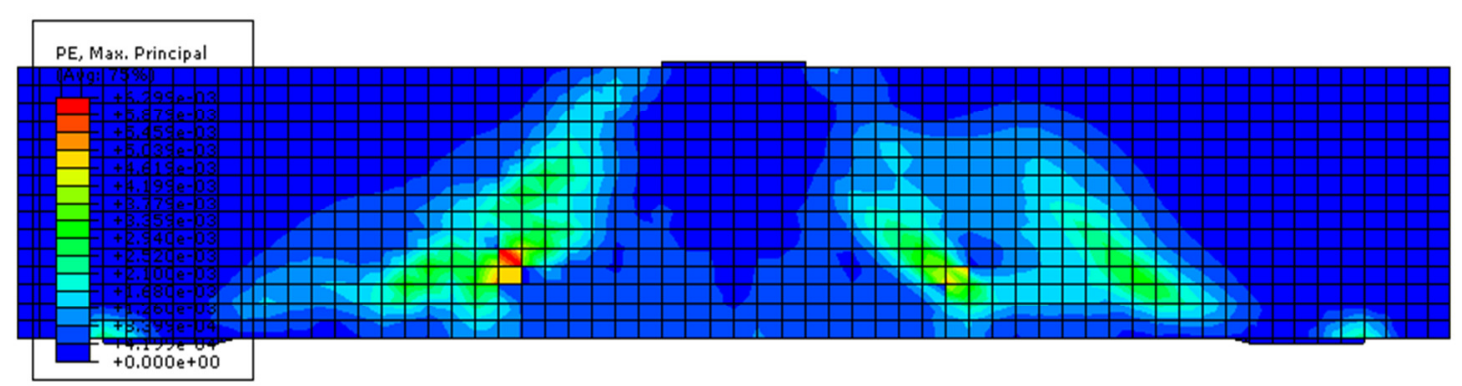

Fig. 13 The ultimate failure damage of the specimen in the FE model in terms of the maximum principal plastic strain

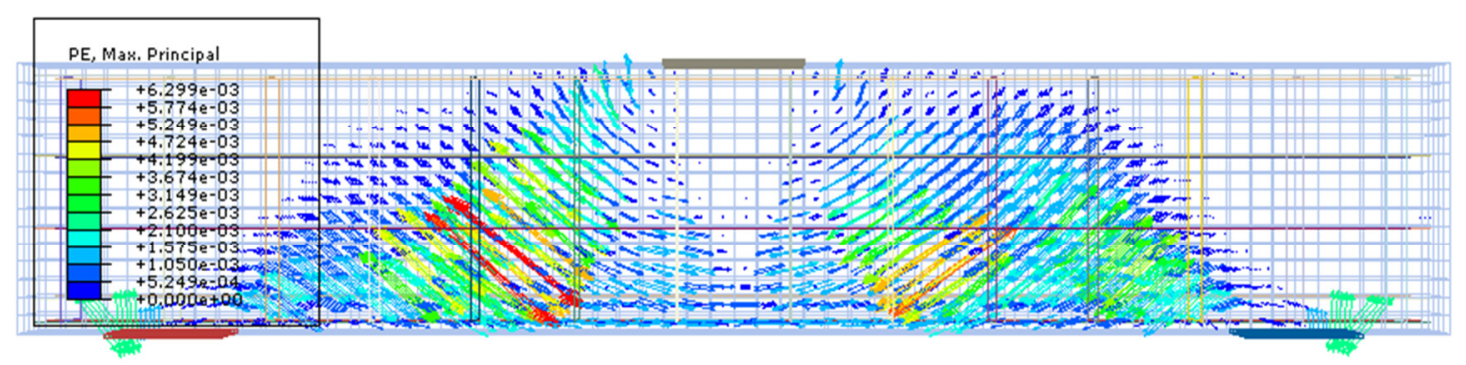

Fig. 14 The direction of the maximum principal plastic strain at the ultimate loading stage

Cracks initiate when the values of the maximum principal plastic strains are positive, and the direction of the cracks is perpendicular to the direction of these strains [8]. The damage distribution visualized in Fig. 13 and Fig. 14, in which the maximum principal plastic strains are vastly concentrated in the midlength of the diagonal strut, resembles with the experimentally observed damage in Fig. 12. The direction of the critical shear crack, running from loading point to the support and responsible for the ultimate failure of the beam, in Fig. 14 is closely perpendicular to the directions of strains depicted in Fig. 12.

Additionally, the contour plots of the minimum principal plastic strain (PE-Min. principal) and its direction are depicted in Fig. 15 and Fig. 16, respectively. In another perspective, Fig. 16 shows the path in which the applied load travels from the loading point to the supports. The compression struts manifesting the bottle-shaped diagonal struts and indicating a clear behavior of an RC deep beam can be seen in Fig. 16. To sum up, it can be argued that the FE model successfully replicate the damage distribution that is manifested by the RC deep beam specimen during the ultimate loading stage of the experimental test. 


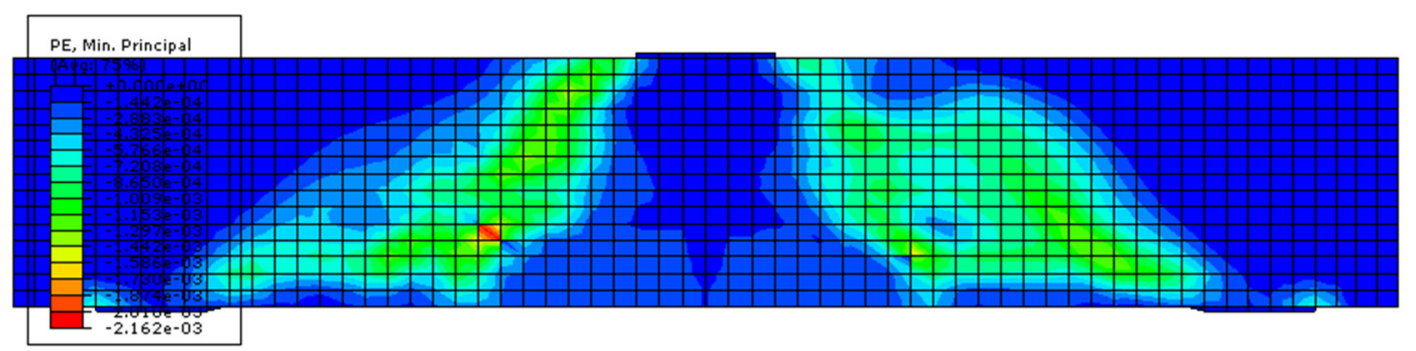

Fig. 15 The ultimate failure damage of the specimen in the FE model in terms of minimum principal plastic strain

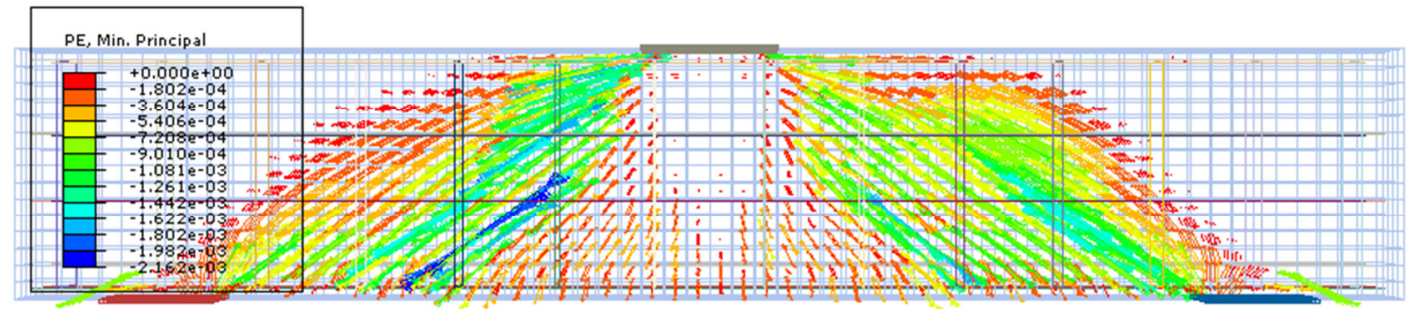

Fig. 16 The direction of the minimum principal plastic strain at the ultimate loading stage

\section{Conclusions}

This paper demonstrated a finite element modeling technique that can be applied for nonlinear analysis of reinforced concrete structures. Particularly, the simulation technique focused on the nonlinear behavior of concrete which was based on the CDP material model available in the FEA based software, ABAQUS. An RC deep beam specimen tested experimentally in an earlier research study was simulated, and the output results were achieved under a considerable degree of accuracy.

The simulated FE model presented the excellent agreement with the experimentally tested beam specimen which manifested the brittle shear failure at the ultimate failure stage. While the ultimate load-carrying capacity of the beam specimen predicted by the FE model was lower by $0.75 \%$, the corresponding displacement was higher by $6.92 \%$ compared to the experimental test results.

The constitutive models and damage parameters for the concrete that are proposed by earlier researchers and adopted in this research demonstrated the adequacy in reflecting the precise behavior of the RC deep beam. The damage distribution predicted by the FE model was close to the damage that occurred during the ultimate failure loading stage of the experimental test.

Additionally, the constitutive model and damage parameters of the concrete material adopted in this study can be applied for the investigation of various RC structures including the parameterized nonlinear finite element analysis to investigate the nonlinear behavior of RC deep beams.

\section{Conflicts of Interest}

The author declares no conflict of interest.

\section{References}

[1] Y. Dere, A. Asgari, E. D. Sotelino, and G. C. Archer, "Failure Prediction of Skewed Jointed Plain Concrete Pavements Using 3D FE Analysis," Engineering Failure Analysis, vol. 13, no. 6, pp. 898-913, September 2006.

[2] A. R. Mohamed, M. S. Shoukry, and J. M. Saeed, "Prediction of the Behavior of Reinforced Concrete Deep Beams with Web Openings Using the Finite Element Method," Alexandria Engineering Journal, vol. 53, no. 2, pp. 329-339, June 2014.

[3] Building code Requirements for Structural Concrete, ACI 318-14, ACI Standard, 2014. 
[4] G. Hussein, S. H. Sayed, N. E. Nasr, and A. M. Mostafa, "Effect of Loading and Supporting Area on Shear Strength and Size Effect of Concrete Deep Beams," Ain Shams Engineering Journal, vol. 9, no. 4, pp. 2823-2831, December 2018.

[5] B. S. Young, J. M. Bracci, P. B. Keating, and M. B. D. Hueste, "Cracking in Reinforced Concrete Bent Caps," Structural Journal, vol. 99, no. 4, pp. 488-498, 2002.

[6] P. Rai and K. Phuvoravan, "Shear Behavior of RC Deep Beam Strengthened by V-Shaped External Rods," International Journal of Engineering Technology Innovation, vol. 10, no. 1, pp. 41-59, January 2019.

[7] A. Earij, G. Alfano, K. Cashell, and X. Zhou, "Nonlinear Three-Dimensional Finite-Element Modelling of ReinforcedConcrete Beams: Computational Challenges and Experimental Validation,” Engineering Failure Analysis, vol. 82, pp. 92-115, December 2017.

[8] “Abaqus Users Manual, Version 6.13-2,” http://130.149.89.49:2080/v6.11/books/usb/default.htm, August 02, 2020.

[9] J. Lubliner, J. Oliver, S. Oller, and E. Oñate, “A Plastic-Damage Model for Concrete,” International Journal of Solids and Structures, vol. 25, no. 3, pp. 299-326, 1989.

[10] J. Lee and G. L. Fenves, "Plastic-Damage Model for Cyclic Loading of Concrete Structures," Journal of Engineering Mechanics, vol. 124, no. 8, pp. 892-900, August 1998.

[11] A. Hamoda, A. Basha, S. Fayed, and K. Sennah, "Experimental and Numerical Assessment of Reinforced Concrete Beams with Disturbed Depth," International Journal of Concrete Structures and Materials, vol. 13, no. 1, p. $55,2019$.

[12] H. Behnam, J. S. Kuang, and B. Samali, "Parametric Finite Element Analysis of RC Wide Beam-Column Connections," Computers \& Structures, vol. 205, pp. 28-44, August 2018.

[13] J. D. Nzabonimpa, W. K. Hong, and J. Kim, "Nonlinear Finite Element Model for the Novel Mechanical Beam-Column Joints of Precast Concrete-Based Frames," Computers \& Structures, vol. 189, pp. 31-48, September 2017.

[14] A. S. Genikomsou and M. A. Polak, "Finite Element Analysis of Punching Shear of Concrete Slabs Using Damaged Plasticity Model in ABAQUS," Engineering Structures, vol. 98, pp. 38-48, September 2015.

[15] V. Birtel and P. Mark, "Parameterised Finite Element Modelling of RC Beam Shear Failure," ABAQUS Users' Conference, 2006, pp. 95-108.

[16] A. Demir, N. Caglar, and H. Ozturk, "Parameters Affecting Diagonal Cracking Behavior of Reinforced Concrete Deep Beams," Engineering Structures, vol. 184, pp. 217-231, April 2019.

[17] S. Popovics, “A numerical Approach to the Complete Stress-Strain Curve of Concrete," Cement Concrete Research, vol. 3, no. 5, pp. 583-599, September 1973.

[18] E. Thorenfeldt, A. Tomaszewicz, and J. J. Jensen, "Mechanical Properties of High-Strength Concrete and Applications in Design," Symposium on Utilization of High-Strength Concrete (Stavanger, Norway), Tapir, Trondheim, Norway, 1987.

[19] A. Belarbi and T. T. Hsu, "Constitutive Laws of Concrete in Tension and Reinforcing Bars Stiffened by Concrete," Structural Journal, vol. 91, no. 4, pp. 465-474, July 1994.

[20] X. B. D. Pang and T. T. Hsu, "Behavior of Reinforced Concrete Membrane Elements in Shear," Structural Journal, vol. 92, no. 6, pp. 665-679, November 1995.

Copyright $(\mathrm{C}$ by the authors. Licensee TAETI, Taiwan. This article is an open access article distributed under the terms and conditions of the Creative Commons Attribution (CC BY-NC) license (https://creativecommons.org/licenses/by-nc/4.0/). 